\title{
Early intervention in panic: randomized controlled trial and cost-effectiveness analysis
}

\author{
Peter Meulenbeek*1,2, Godelief Willemse ${ }^{3}$, Filip Smit ${ }^{1,3}$, Anton van Balkom ${ }^{4}$, \\ Philip Spinhoven ${ }^{5}$ and Pim Cuijpers ${ }^{1,3}$
}

\begin{abstract}
Address: ${ }^{1}$ Department of Clinical Psychology and EMGO Institute, VU-University, Amsterdam, The Netherlands, ${ }^{2}$ GGNet, Community Mental Health Center, Warnsveld, The Netherlands, ${ }^{3}$ Trimbos instituut (Netherlands Institute of Mental Health and Addiction), Utrecht, The Netherlands, ${ }^{4}$ Department of Psychiatry and EMGO Institute, VU-University Medical Center, Amsterdam, The Netherlands and ${ }^{5}$ Unit of Clinical Psychology, Institute of Psychological Research and Department of Psychiatry, Leiden University Medical Center, Leiden University, Leiden, The Netherlands

Email: Peter Meulenbeek* - p.meulenbeek@compaqnet.nl; Godelief Willemse - gwillemse@telfort.nl; Filip Smit - fsmit@trimbos.nl; Anton van Balkom - vanbalkom@ggzba.nl; Philip Spinhoven - SPINHOVEN@fsw.leidenuniv.nl; Pim Cuijpers - p.cuijpers@psy.vu.nl

* Corresponding author
\end{abstract}

Published: 27 November 2008

Trials 2008, 9:67 doi:10.1186/1745-62/5-9-67

This article is available from: http://www.trialsjournal.com/content/9/I/67

(C) 2008 Meulenbeek et al; licensee BioMed Central Ltd.

This is an Open Access article distributed under the terms of the Creative Commons Attribution License (http://creativecommons.org/licenses/by/2.0), which permits unrestricted use, distribution, and reproduction in any medium, provided the original work is properly cited.
Received: 24 October 2008
Accepted: 27 November 2008

\begin{abstract}
Background: Panic disorder (PD) is a common, severe and persistent mental disorder, associated with a high degree of distress and occupational and social disability. A substantial proportion of the population experiences subthreshold and mild PD and is at risk of developing a chronic PD. A promising intervention, aimed at preventing panic disorder onset and reducing panic symptoms, is the 'Don't Panic' course. It consists of eight sessions of two hours each. The purpose of this study is to evaluate the effectiveness of this early intervention - based on cognitive behavioural principles - on the reduction of panic disorder symptomatology. We predict that the experimental condition show superior clinical and economic outcomes relative to a waitlisted control group.
\end{abstract}

Methods/design: A pragmatic, pre-post, two-group, multi-site, randomized controlled trial of the intervention will be conducted with a naturalistic follow-up at six months in the intervention group. The participants are recruited from the general population and are randomized to the intervention or a waitlist control group. The intervention is offered by community mental health centres. Included are people over 18 years of age with subthreshold or mild panic disorder, defined as having symptoms of PD falling below the cut-off of 13 on the Panic Disorder Severity Scale-Self Report (PDSS-SR). Primary outcomes are panic disorder and panic symptoms. Secondary outcomes are symptoms of agoraphobia, anxiety, cognitive aspects of panic disorder, depressive symptoms, mastery, health-related quality of life, and cost-effectiveness. We will examine the following variables as potential mediators: cognitive aspects of panic disorder, symptoms of agoraphobia, anxiety and mastery. Potential moderating variables are: socio-demographic characteristics, panic disorder, agoraphobia, treatment credibility and mastery.

Discussion: This study was designed to evaluate the (cost) effectiveness of an early intervention based on cognitive behavioural principles. The strong external validity is one of the strengths of the study design.

Trial registration: Current Controlled Trials ISRCTN33407455. 


\section{Background}

Panic disorder (PD) affects $2 \%$ to $3 \%$ of the adult population each year [1-3], and is associated with a large burden of disease, considerable medical consumption and extensive loss of productivity [4-7]. The incidence of PD is high (about 35\% of all PD cases are new cases, having emerged only in the last year; [1]), indicating the importance of prevention and early intervention in PD.

A substantial proportion of the population suffers from subthreshold PD [8-10]. Subthreshold PD can be defined as the presence of some symptoms of $\mathrm{PD}$, not meeting the DSM-IV diagnostic criteria. In a study reported by Norton, Dorward and Cox [11], 35.9\% of the 256 presumably normal subjects reported experiencing one or more panic attacks in the past year, with $22.7 \%$ experiencing one or more panic attacks within the past three weeks. These subjects may be at risk of developing full-blown PD $[12,13]$.

PD sufferers are often not recognized as such [4]. Furthermore, although there are effective treatments for PD [14], PD sufferers do not always receive empirically supported treatments; even if this were the case, the proportion of burden averted would still be low [15]. In addition, it usually takes many years before treatment is sought, and when not properly treated the prognosis is poor and the disorder may become chronic [16]. Prevention and early intervention in PD are therefore of great interest, and a panic prevention and early intervention program delivered to subjects with subthreshold or mild PD may decrease current panic disorder symptomatology.

Studies on prevention and early intervention in anxiety disorders indicate that prevention of anxiety disorders through cognitive-behavioural interventions can be successful [17-19]. Only a few studies have been conducted in this field. Gardenswartz and Craske [20] tested a prevention program for panic disorder. Participants consisted of college students who had experienced a panic attack in the last 12 months and had at least moderate anxiety sensitivity (ASI score of 16 or higher; [21]), but did not meet the criteria for panic disorder (CIDI; [22]). They were randomly assigned to either a one-day prevention workshop $(n=55)$ or a wait-list control $(n=66)$. The one-day (fivehour) workshop entailed psycho-education, breathing retraining, cognitive restructuring, interoceptive exposure and 'in vivo' exposure. At six-month follow-up nine participants $(13.6 \%)$ from the wait-list group and only one participant $(1.8 \%)$ from the workshop group had developed panic disorder, indicating a favourable treatment response.

In a study by Swinson, Soulios, Cox, and Kuch [23], 33 adults with panic attacks seen in two emergency rooms were randomly assigned to groups receiving reassurance $(\mathrm{n}=16)$ or exposure instruction $(\mathrm{n}=17)$. Subjects who had received the exposure instruction significantly improved over the six-month follow-up period for symptoms of depression, avoidance, and panic frequency, whereas subjects receiving reassurance did not improve for any of these variables.

Despite methodological limitations, such as limited generalizability, small sample size and short follow-up periods, the results of these studies suggest that prevention of panic disorder is a promising option.

The aim of this study is to examine the effectiveness of an early intervention for panic symptoms in a sample of selfreferred people presenting with subthreshold or mild PD in a randomized controlled trial. We predict that the intervention will show superior effects in reducing panic disorder symptomatology, compared to a waitlisted control group. Furthermore, an economic analysis will be performed to assess the cost-effectiveness of the intervention.

\section{Methods \\ Study design}

The study was designed as a pragmatic, multi-site, randomized controlled trial of the 'Don't Panic' course versus a wait-list control group. Measurements were taken at baseline measurement (T0) followed by a posttest measurement after three months (T1). To monitor effect maintenance over time, the experimental group underwent a prolonged follow-up measurement nine months after baseline, i.e., six months after the end of the intervention (T2). The study was designed to mimic the Dutch health care system as naturalistically as possible in terms of patient recruitment and the manner in which intake, offering the intervention, and monitoring outcomes are conducted. This was done to enhance external validity. The randomization took place after administration of the International Neuropsychiatric Interview Plus (MINIPlus; [24]), and was carried out centrally by an independent third party. A blocked randomization scheme was used, stratified by mental health centre, subthreshold PD versus mild $\mathrm{PD}$, and by presence versus absence of cooccurring agoraphobia. The latter was included because it was assumed that agoraphobia may be a prognostically relevant factor for outcome in PD. This procedure ensures that participants with and without PD or agoraphobia were equally distributed across both trial arms. See Figure 1 for participants' flow through the study. The trial protocol was approved by an independent medical ethics committee (METIGG).

\section{Sample size}

Power analysis indicated that 129 participants per condition are required in order to detect a difference in symptom reduction, equivalent to a standardized effect size of 


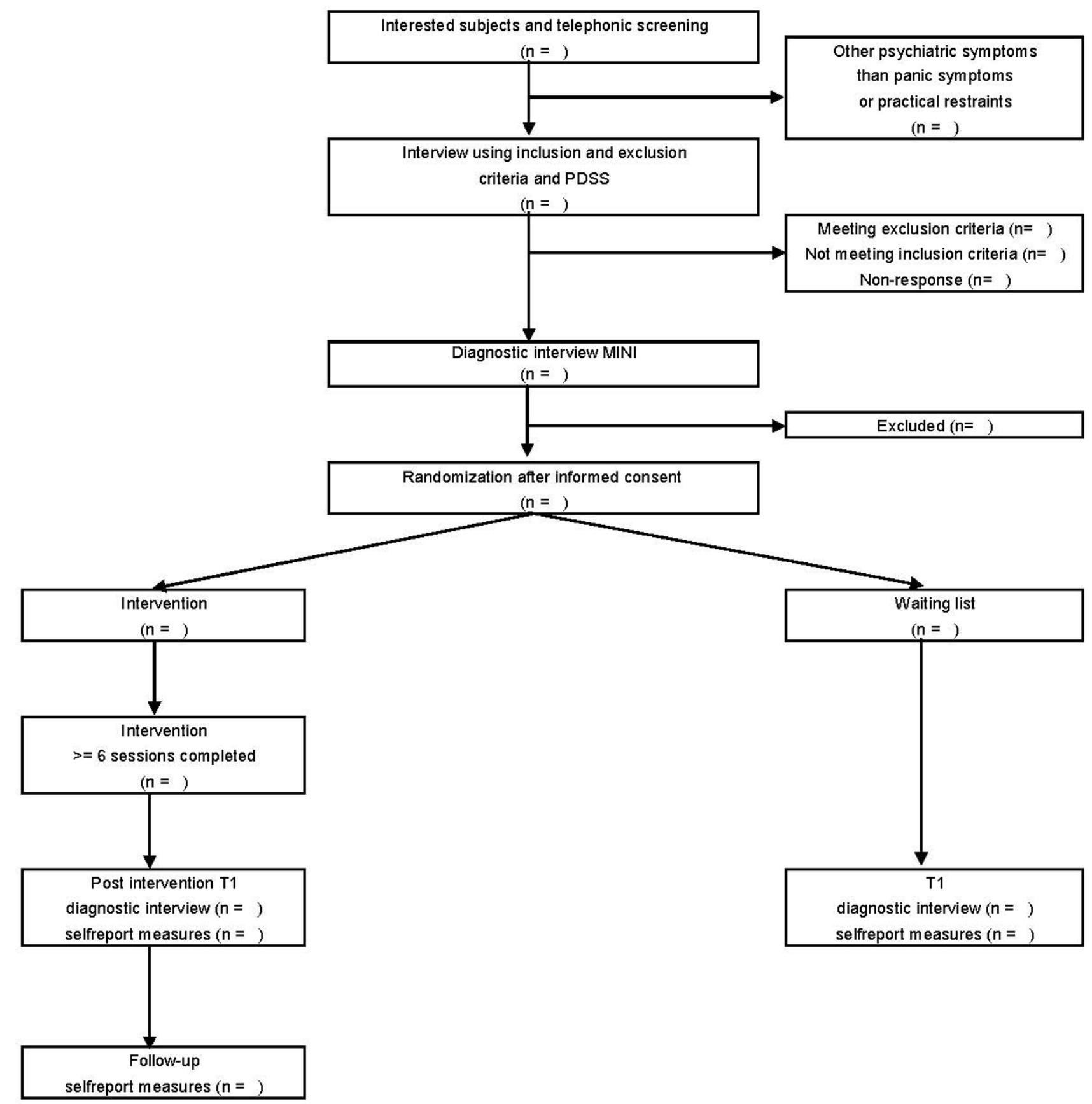

Figure I

Participants' flow through the study. PDSS: Panic Disorder Severity Scale-Self Report, MINI: Mini-International Neuropsychiatric Interview-Plus.

at least 0.35 in a two-sided test at alpha $=0.05$ and $\mathrm{a}$ power of $(1$-beta $)=0.80$.

\section{Study sample}

Participants were recruited from the general adult population in the Netherlands. They were eligible when over 18 years of age and presenting with subthreshold or mild panic disorder, defined as having symptoms of PD falling below the cut-off of 13 on the Panic Disorder Severity Scale-Self Report (PDSS-SR) [25,26]. Exclusion criteria were more severe PD (PDSS-SR $\geq 13$ ), other current severe psychiatric symptoms or social problems, suicidal inten- 
tion warranting treatment or likely to interfere with participation in the group course, and current psychological treatment for PD-related complaints. Other exclusion criteria were illness requiring immediate medical attention, and inability to function independently as well as in a group. People meeting one of the exclusion criteria were advised to seek regular treatment. If a participants used medication for anxiety or depression, it was agreed not to change the medication during the study period. Following a thorough explanation of the study procedures, written informed consent was obtained.

\section{Recruitment}

Participants were recruited from the general population through media announcements and via the internet. For screening, the standard procedures employed by the Community Mental Health Centers were used. Firstly, people who showed interest were given more information about the course and the study. They also had an initial screening interview by telephone to ascertain the presence of panic symptoms. Secondly, potential participants had an interview with an experienced psychologist from a Community Mental Health Centre. In this interview, the exclusion criteria as described above were checked. In addition, potential participants were interviewed by trained interviewers from the Trimbos Institute (Netherlands Institute of Mental Health and Addiction) using the MINI-Plus [24]. This was done to assess the DSM-IV PD status, the presence of current co-morbid agoraphobia, and to exclude the presence of current severe major depressive disorder.

\section{Interventions}

We developed an early intervention for panic symptoms, called the 'Don't panic' course. The course is based on cognitive-behavioural principles and makes use of interventions that have appeared effective in the treatment of the full-blown disorder [27-29]. This intervention was developed specifically for adults. It consists of eight weekly sessions of two hours each in groups of six to 12 participants. The 'Don't panic' course makes use of a course manual [30], to be used by the psychologist and prevention worker offering the intervention, and an accompanying workbook for the participants [31]. The course instructors received a one-day training in offering the course and working with the course manual, to ensure integrity of the intervention delivery. Participants were taught to examine their panic attacks and the possible causes, to use techniques to influence their anxiety, and to develop skills to improve how they cope with panic attacks. The course includes (a) a psycho-educational element about the nature and physiology of anxiety and panic attacks, (b) life-style changes to improve physical condition, (c) stress management to prevent constant tension by learning effective ways to cope with stress, (d) relaxation training to reduce physiological arousal, (e) cognitive restructur- ing to challenge and correct dysfunctional cognitions of panic and anxiety, (f) interoceptive exposure to reduce the fear of somatic sensations, (g) 'in vivo' exposure to reduce agoraphobic avoidance, and $(\mathrm{h})$ techniques aimed at relapse prevention. During the course the participants had to evaluate their progress. After three months following completion of the course a booster session was offered. Each session was structured to include a discussion of homework assignments, feedback, rehearsals, information about the upcoming topic and practical skills training. The intervention was extensively pilot-tested before entering the clinical trial stage.

The control condition consisted of a waiting list. Waitlisted people were told that they could start the course after four months. They were not kept waiting for the extended follow-up for ethical reasons.

\section{Instruments}

The instruments used are well validated and frequently applied in international studies. Table 1 represents the measurements conducted at the different assessment times. Most of the self-report questionnaires were used for all three measurements and completed at home. The MINI-Plus was conducted by telephone at T0 and T1.

\section{Primary outcome measures}

Primary outcome measures include the severity of panic symptoms and PD diagnoses.

\section{Severity of panic symptoms}

For severity of panic symptoms the Dutch adaptation of the PDSS-SR [25,32] was used. The PDSS-SR contains

Table I: Instruments at different assessment times

\begin{tabular}{llll}
\hline & T0 & TI (3 months) & T2 (9 Months) \\
\hline PDSS-SR & $\mathrm{X}$ & $\mathrm{X}$ & $\mathrm{X}$ \\
MINI-Plus & $\mathrm{X}$ & $\mathrm{X}$ & \\
MI & $\mathrm{X}$ & $\mathrm{X}$ & $\mathrm{X}$ \\
HADS-Anx & $\mathrm{X}$ & $\mathrm{X}$ & $\mathrm{X}$ \\
PAI & $\mathrm{X}$ & $\mathrm{X}$ & $\mathrm{X}$ \\
BDI-II & $\mathrm{X}$ & $\mathrm{X}$ & $\mathrm{X}$ \\
Mastery & $\mathrm{X}$ & $\mathrm{X}$ & $\mathrm{X}$ \\
EQ-5D & $\mathrm{X}$ & $\mathrm{X}$ & $\mathrm{X}$ \\
TIC-P & $\mathrm{X}$ & $\mathrm{X}$ & $\mathrm{X}$ \\
Evaluation & & $\mathrm{X}$ & \\
Demografics & $\mathrm{X}$ & & \\
AUDIT & $\mathrm{X}$ & & \\
TCQ & $\mathrm{X}$ & &
\end{tabular}

PDSS-SR: Panic Disorder Severity Scale-Self Report, MINI-Plus: Mini International Neuropsychiatric Interview-Plus, MI: Mobility Inventory, HADS-Anx: Hospital Anxiety and Depression Scale, subscale Anxiety, PAI: Panic Appraisal Inventory, BDI-Il: Beck Depression Inventorysecond edition, EQ-5D: EuroQol Questionnaire, TIC-P: Trimbos and Institute of Medical Technology Assessment Questionnaire on Costs Associated with Psychiatric Illness, AUDIT: Alcohol Use Disorders Identification Test, TCQ: Treatment Credibility Questionnaire. 
seven items that assess the severity of seven dimensions of panic disorder and associated symptoms: 1 ) frequency of panic attacks; 2) distress during panic attacks; 3 ) anticipatory anxiety (worry about future panic attacks); 4) agoraphobic fear and avoidance; 5) interoceptive fear and avoidance (i.e., apprehension and avoidance of bodily sensations); 6) impairment of or interference in work functioning; and 7) impairment of or interference in social functioning. The PDSS-SR generates a total score ranging from 0 to 28 , with a higher score indicating more severe panic symptoms. The questionnaire has good psychometric properties (Cronbach's alpha $=0.92$; intraclass correlation coefficient $=0.81$ ) [33]. A cut-off score of eight may discriminate between the presence or absence of current DSM-IV panic disorder [25,32] and a cut-off score of thirteen may discriminate between mild and severe panic disorder [26,32].

\section{Diagnosis}

To assess the DSM-IV panic disorder status the Dutch version of MINI-Plus [24,34] was used. The MINI-Plus is a short, structured, diagnostic interview for DSM-IV and ICD-10 psychiatric disorders, designed for use by professional interviewers. Validation of the MINI in relation to the Structured Clinical Interview for DSM-III-R Patient Version and the Composite International Diagnostic Interview showed good to very good kappa values [24]. To exclude serious major depressive disorder this section was supplemented with the Sheehan Disability Scale [35]. Subjects who reported at least two areas of role functioning with severe role impairment due to a depressive disorder were excluded from the study. The interviews were conducted by experienced interviewers who received one day's training. The interviews were conducted by telephone, as several findings provide qualified justification for this mode of assessing psychiatric disorders [36,37]. The interviewers were blind with respect to the randomization status of the participants.

\section{Secondary outcome measures}

Secondary outcome measures include symptoms of agoraphobia, anxiety symptoms, cognitive measure for panic, depressive symptoms, perceived control, quality of life and cost-effectiveness.

\section{Symptoms of agoraphobia}

For symptoms of agoraphobia the Dutch adaptation of the Mobility Inventory (MI; $[38,39])$ was used. The MI assesses agoraphobic avoidance. The total score ranges from 1 to 5, with a higher score indicating more avoidance. The MI has been found to have good test-retest reliability, high internal consistencies, and reasonably concurrent validity $[38,39]$.

\section{Anxiety symptoms}

The subscale for anxiety of the Dutch version of the Hospital Anxiety and Depression Scale (HADS) was used to indicate the possible presence of anxiety states. The HADS was developed as a brief self-report screening scale to detect states of depression and anxiety in the setting of a medical out-patient clinic [40]. A validation study of the Dutch version of the HADS by Spinhoven et al. [41] confirmed the two-factor structure and showed $\alpha$ 's ranging from $0.71-0.90$ for the total scale and both subscales. The subscale for anxiety consists of seven items with a score range of $0-21$. A high score means a higher state of anxiety.

\section{Cognitive measure for panic}

As a cognitive measure for panic disorder the Dutch version of the Panic Appraisal Inventory $[42,43]$ was used. The PAI measures cognitive aspects of panic disorder, such as (PAI-anticipation) perceived likelihood of panic occurrence, (PAI-consequences) perceived negative consequences of panic occurrence, and (PAI-coping) perceived self-efficacy in coping with panic. Each of the three subscales of the PAI consists of 15 items; the scale score ranges from 0 to 100, and a higher score means a more negative cognitive state. The PAI has excellent psychometric properties; it has been shown to be reliable, valid and quite sensitive to change after therapy $[42,43]$.

\section{Depressive symptoms}

The Dutch version of the Beck Depression Inventory, second edition, (BDI-II; $[44,45]$ ) was used to assess depressive symptoms. The BDI-II is a 21 -item self-report questionnaire for assessing the severity of depressive symptoms in the past week. The total score ranges from 0 to 63. A high score reflects a higher depression level. The BDI-II has good psychometric properties $[45,46]$.

\section{Perceived control}

The Dutch version of the Mastery-Scale [47] was used to assess locus of control; a higher rating means greater internal locus of control, indicating more feelings of mastery. The total score ranges from 5 to 25 . The Mastery-Scale has good psychometric properties [47].

\section{Quality of life}

As a measure for quality of life the Dutch version of the EuroQol Questionnaire (EQ-5D) [48-50] was used. It contains five dimensions (mobility, self-care, usual activities, pain/discomfort and anxiety/depression), each of which is rated by the respondent as causing 'no problems', 'some problems', or 'extreme problems'. The EQ-5D generates a total of 243 unique health states, each of which is associated with a utility score ranging from 0 (poor health) to 1 (perfect health). The EQ-5D is a validated 
instrument for measuring general health-related quality of life [48-50].

\section{Cost-effectiveness}

For economic evaluation the following costs were examined, using parts of the Trimbos and Institute of Medical Technology Assessment Questionnaire on Costs Associated with Psychiatric Illness (TIC-P)[51]: costs directly related to health care, indirect health care related costs (out-of-pocket costs, costs of informal care), direct costs outside health care (monetary value of production losses caused by absence and reduced productivity).

\section{Additional measures}

To examine the feasibility and acceptability of the intervention, questionnaires were used to evaluate the course by the participants (e.g., questions to evaluate organizational aspects, coaching, content, group sessions, and workbook) at posttest.

To collect demographic information pertaining to the participants, questions concerning gender, age, nationality, living situation, education and occupation were added to the self-report questionnaires.

Furthermore, the AUDIT (Alcohol Use Disorders Identification Test)[52] was used to assess alcohol use and the TCQ (Treatment Credibility Questionnaire)[53] was used for treatment credibility. Both questionnaires have good psychometric properties $[54,55]$ and were used as possible predictor variables.

\section{Analyses}

All analyses were conducted in agreement with the intention to treat principle [56], hence all participants were analyzed in the condition to which they were randomized, and missing endpoints at follow-up were imputed using a regression model with the best available predictors of outcome and the best predictors for dropout. The first set of predictors is required to get the most precise estimates for the missing values; the latter to correct for bias that may stem from differential loss-to-follow-up associated with $\mathrm{T0}$ variables [57].

In all analyses on effectiveness, we controlled for the clustering of data caused by the multi-site character of the study. Clustering violates the assumption of independence of observations, and may thus affect standard errors and $P$ values. So-called 'robust standard errors' and correct $P$ values were obtained using the first-order Taylor series linearization method. All analyses were conducted with Stata $9.0[58]$.

For the primary outcome on PDSS-SR, a Gaussian regression model was used to test the hypothesis of superior intervention effects in the experimental arm compared to the waitlist control group. We calculated between-group effect sizes at posttest by subtracting the mean posttest score of each condition and dividing the difference by the pooled standard deviation (Cohen's $d$ ). In the field of psychological interventions, effect sizes in the range of 0.00 to 0.32 are regarded as small, while effect sizes of 0.33 to 0.55 are moderate, and effect sizes of 0.56 to 1.2 are large [59].

As primary outcome we also compared the proportion of participants manifesting a clinically significant change on the PDSS-SR (responders) across the two groups. Clinically significant change was defined according to the criteria proposed by Jacobson and Truax [60]: a change should move from a dysfunctional distribution to a functional one, and the change should be statistically reliable in the sense that the observed change cannot be put down to measurement error in the PDSS-SR. Because we studied a population with subthreshold and mild PD, we considered scores below one standard deviation of the mean pretest score on the PDSS-SR as falling within the functional range [61]. This binary outcome was then used to obtain the odds ratio (OR) using a logistic regression of the binary outcome on the intervention dummy and the numbers-to-be-treated (NNT) using Gaussian regression.

The sample can be divided in two groups: people with relatively mild manifestations of MINI-DSM-IV panic disorder and those with subthreshold manifestations not meeting the diagnostic criteria. When we focus on the latter group: people at risk of developing panic disorder, we can look at how many of these persons developed PD meeting the diagnostic criteria of the DSM-IV at T1. When we pay attention to the group with mild PD, we can see how many of these persons became PD-free at T1. For the primary outcome on the MINI-Plus we compared the proportion of success across the two groups. Success was defined as: (a) the participant had no PD at T0 and stayed PD free at T1 or (b) the participant had mild PD at T0 and no PD at T1. This yields a binary outcome where failure is coded 0 , and success is coded 1 . In a next step, this binary outcome was used to obtain the OR and the NNT.

The demographic and clinical characteristics of responders versus non-responders, and success versus failure, were compared using Student's $t$ test for independent groups or Pearson's chi-squared tests when appropriate.

For the secondary outcomes on continuous measurement scales, a Gaussian regression model was used to test the hypothesis of superior intervention effects in the experimental arm compared to the wait-list control group. Furthermore, the between-group effect sizes (Cohen's $d$ ) were calculated. To test the maintenance of the effects at six- 
month follow-up we used a paired-samples t test to analyze the difference in mean score of the self-report measures in the experimental group from $\mathrm{T} 0$ to $\mathrm{T} 1, \mathrm{~T} 0$ to $\mathrm{T} 2$ and $\mathrm{T} 1$ to $\mathrm{T} 2$.

To provide a more comprehensive picture of the effects of the intervention, results for the outcomes will also be presented for completers only (defined as participants who attended at least six sessions).

The following variables will be examined as potential mediators: cognitive aspects of panic disorder, symptoms of agoraphobia, anxiety and mastery. Furthermore, potential moderating variables (e.g., socio-demographic characteristics, panic disorder, agoraphobia, treatment credibility and mastery) will be analyzed.

The following costs are examined for economic evaluation: costs directly related to health care, indirect health care related costs (out-of-pocket costs, costs of informal care), direct costs outside health care (monetary value of production losses caused by absence and reduced productivity), as measured with the TIC-P. The mean total costs for each of the conditions at baseline and $\mathrm{T} 1$ were calculated. Then the pre-post difference in costs were calculated to obtain the increase (or decrease) of costs over time in each of the conditions. First, we observed how many participants presented with a clinically significant change on the PDSS-SR across the two groups. The incremental costeffectiveness ratio (ICER) was calculated as the incremental costs for a health gain of a clinically significant change over three months. Next, we observed how many people stayed PD free at T1. The ICER was calculated as the incremental costs for a health gain of a PD-free survival over three months. Furthermore, we calculated the incremental cost-utility ratio (ICUR) across the experimental and control condition. The ICUR represents the incremental costs (or savings) per QALY (Quality Adjusted Life Years, assessed with the EQ-5D) gained in the experimental condition relative to the control condition. By calculating ICUR the results can be compared to other health care interventions. In all cases, uncertainty was assessed by means of non-parametric bootstrapping (2,500 times) of the data of the individual respondents.

All tests were conducted using a two-sided significance level at $\alpha<0.05$.

\section{Discussion}

The purpose of this study is to evaluate the effectiveness of this early intervention based on cognitive behavioural principles on the reduction of panic disorder symptomatology. Furthermore, cost-effectiveness of the intervention is evaluated. We predicted that the experimental condition would show superior effects in reducing panic symptoms, improving quality of life and will be cost-effective despite the additional costs introduced by offering the 'Don't Panic' intervention in the first place. This may be regarded to be an important finding, because, to our knowledge, this is the first study that examines the effectiveness of an early intervention for self-referred adults with subthreshold or mild panic disorder, offered by community mental health centres.

\section{Strengths and limitations}

We changed the original protocol by including people with mild PD (PDSS < 13) and, as a consequence, not excluding participants with PD according to the MINIPlus. People with mild PD are known to be shy in asking professional help. A low threshold intervention may appear accessible and acceptable for these people. In the Dutch mental health care system people with subthreshold or mild mental disorders are usually offered courses as a first step in a stepped-care model in mental health [6264]. To strengthen the external validity of the trial we decided to include people with mild PD. Furthermore, the results may be highly generalizable as the intervention is studied in its natural setting and the recruitment strategies of both the study and the community mental health centres that offer the course are very similar. Another strength of this trial is the use of an structured diagnostic interview for DSM-IV and ICD-10 psychiatric disorders (MINIPlus). This makes it possible to analyze changes in PD status, and for randomization to be stratified by subthreshold PD versus mild PD, and by presence versus absence of co-occurring agoraphobia. The latter was done because it was assumed that agoraphobia is a prognostic relevant factor for treatment response in PD.

We recognize a number of limitations in this study. First, because of the absence of a placebo control, it is not clear whether nonspecific components of the intervention, such as social cohesion and expectation of gain contribute to the possible early intervention effect. Future research should use placebo controlled designs to overcome this problem. Secondly, the time available to study a change in PD status was only three months. For ethical reasons the control group received the intervention a few weeks after $\mathrm{T} 1$. For future research to study a change in PD status an extended period is advised. Thirdly, because of financial limitations we could not raise the sample size, so the change of protocol by including mild PD caused a lack of power to analyze a reduction of incidence of PD according to the MINI-Plus. Fourthly, there is no control condition at six-month follow-up after the course. Therefore, definite conclusions that the possible effects at six-month follow-up may be related to the intervention are not allowed. Finally, the extended follow-up period was only six months following the conclusion of the course, but longer follow-up periods are needed to know how long the possible effects will persist. 
Notwithstanding the limitations, the development and research of an early intervention in panic disorder - a severe and persistent mental disorder, associated with a large burden of disease and extensive economic costs - is of the utmost importance.

\section{Competing interests}

The authors declare that they have no competing interests.

\section{Authors' contributions}

All authors contributed to the design of the study. PM and GW drafted the manuscript and took care of the recruitment of participants and data collection. FS, GW, PS and PM will perform the statistical analyses. PC, AvB and PS will act as a Quality Assurance Committee for this trial. All authors provided comments, read and approved the final manuscript.

\section{Acknowledgements}

Supported by the Netherlands Health Research Council, The Hague (ZonMw) grant \# 50-50I I0-98-035/6200.0006 (awarded to Dr. Smit). The authors thank Ms Jessica Herzmanatus (GGNet) and Ms Rianne van der Zanden (Trimbos Institute) for their help with the development of the 'Don't Panic' intervention; and the trainers and trainees for their valuable help in making this study possible.

\section{References}

I. Bijl R, De Graaf R, Ravelli A, Smit F, Vollenbergh W: Gender and age specific first incidence of DSM-III-R psychiatric disorders in the general population. Results from the Netherlands Mental Health Survey and Incidence Study (NEMESIS). Social Psychiatry and Psychiatric Epidemiology 2002, 37:372-379.

2. Kessler RC, McGonagle KA, Zhao S, Nelson CB, Hughes M, Eshleman $\mathrm{S}$, Wittchen HU, Kendler KS: Lifetime and I 2-month prevalence of DSM-III-R psychiatric disorders in the United States. Results from the National Comorbidity Survey. Archives of General Psychiatry 1994, 51:8-19.

3. Eaton WW, Kessler RC, Wittchen HU, Magee WJ: Panic and Panic Disorder in the United States. American Journal of Psychiatry 1994, 151:413-420.

4. Harvison K, Woodruff-Borden J, Jeffery S: Mismanagement of Panic Disorder in Emergency Departments: Contributors, Costs, and Implications for Integrated Models of Care. Journal of Clinical Psychology in Medical Settings 2004, I I (3):2 I 7-232.

5. Laitinen-Krispijn S, Bijl R: Mental disorders and employee sickness absence: The Nemesis study. Social Psychiatry and Psychiatric Epidemiology 2000, 35:7I-77.

6. Marciniak M, Lage M, Landbloom R, Dunayevich E, Bowman L: Medical and Productivity Costs of Anxiety Disorders: Case Control Study. Depression and Anxiety 2004, 19: I I 2-120.

7. Smit F, Cuijpers P, Oostenbrink J, Batelaan N, De Graaf R, Beekman A: Costs of Nine Common Mental Disorders: Implications for Curative and Preventive Psychiatry. J Ment Health Policy Econ 2006, 9(4): 193-200.

8. Norton GR, Cox BJ, Malan J: Nonclinical panickers: A critical review. Clinical Psychology Review 1992, I 2:121-139.

9. Reed V, Wittchen HU: DSM IV panic attacks and panic disorder in a community sample of adolescents and young adults: how specific are panic attacks? Journal of Psychiatric Research 1998, 32:335-345.

10. Batelaan N, De Graaf R, Van Balkom A, Vollebergh W, Beekman A: Thresholds for health and thresholds for illness: panic disorder versus subthreshold panic disorder. Psychological Medicine 2007, 37:247-256.

11. Norton GR, Dorward J, Cox BJ: Factors associated with panic attacks in nonclinical subjects. Behavior Therapy 1986, 17:239-252.
12. Ehlers A: A I-year prospective study of panic attacks: Clinical course and factors associated with maintenance. Journal of Abnormal Psychology 1995, 104:164-172.

13. Katerndahl DA: Progression of limited symptom attacks. Depression and Anxiety 1999, 9:138-I40.

14. Furukawa TA, Watanabe N, Churchill R: Psychotherapy plus antidepressant for panic disorder with or without agoraphobia. British Journal of Psychiatry 2006, I 88:305-3I2.

15. Andrews G, Issakidis C, Sanderson K, Corry J, Lapsley H: Utilising survey data to inform public policy: comparison of the costeffectiveness of treatment of ten mental disorders. British Journal of Psychiatry 2004, 184:526-533.

16. Liebowitz MR: Panic Disorder as a Chronic Illness. The Journal of Clinical Psychiatry 1997, 58(SuppI I 3):5-8.

17. Dadds MR, Spence SH, Holland DE, Barrett PM, Laurens KR: Prevention and early intervention for anxiety disorders: A controlled trial. Journal of Consulting and Clinical Psychology 1997, 65:627-635.

18. Schmidt NB, Eggleston AM, Woolaway-Bickel K, Fitzpatrick KK, Vasey MW, Richey JA: Anxiety Sensitivity Amelioration Training (ASAT): A longitudinal primary prevention program targeting cognitive vulnerability. Journal of Anxiety Disorders 2007, 21:302-319.

19. Seligman MEP, Schulman P, DeRubeis RJ, Hollon SD: The prevention of depression and anxiety. Prevention and Treatment 1999, 2(I): pre0020008a.html].

20. Gardenswartz CA, Craske MG: Prevention of Panic Disorder. Behavior Therapy 200I, 32:725-737.

21. Reiss S, Peterson RA, Gursky M, McNally RJ: Anxiety, sensitivity, anxiety frequency, and the prediction of fearfulness. Behaviour Research and Therapy 1986, 24:1-8.

22. World Health Organization: Composite International Diagnostic Interview (CIDI), Version 2.I Geneva: WHO; 1997.

23. Swinson RP, Soulios C, Cox BJ, Kuch K: Brief treatment of emergency room patients with panic attacks. Am J Psychiatry 1992, 149(7):944-946.

24. Sheehan DV, Lecrubier $Y$, Sheehan $K H$, Amorim P, Janavs J, Weiller E, Hergueta T, Baker R, Dunbar GC: The Mini International Neuropsychiatric Interview (MINI): The development and validation of structured diagnostic psychiatric interview for DSM-IV and ICD-I0. Journal of Clinical Psychiatry 1998, 59(Suppl 20):22-33.

25. Shear MK, Rucci P, Williams J, Frank E, Grochocinski V, Vander Bilt J, Houck P, Wang T: Reliability and validity of the panic disorder severity scale: replication and extension. Journal of Psychiatric Research 200I, 35:293-296.

26. Michelson D, Allgulander C, Dantendorfer K, Knezevic A, Maierhofer D, Micev V, Paunovic VR, Timotijevic I, Sarkar N, Skoglund L, Pemberton SC: Efficacy of usual antidepressant dosing regimens of fluoxetine in panic disorder: randomised, placebo-controlled trial. The British Journal of Psychiatry 200 I, I79:5 I4-5I8.

27. Bakker A: Recente ontwikkelingen in de behandeling van paniekstoornis en agorafobie [Recent developments in the treatment of panic disorder and agoraphobia]. Tijdschrift voor Psychiatrie (Dutch Journal of Psychiatry) 200I, 43(6):385-393.

28. Margraf J, Barlow DH, Clark DM, Telch MJ: Psychological treatment of panic: Works in progress on outcome, active ingredients, and follow-up. Behaviour Research and Therapy 1993, $3 \mathrm{I}: 1-8$.

29. Van Balkom AJLM, Bakker A, Spinhoven P, Blaauw BMJW, Smeenk S, Ruesink $B$ : A meta-analysis of the treatment of panic disorder with or without agoraphobia: A comparison of psychopharmacological, cognitive-behavioral, and combination treatments. Journal of Nervous and Mental Disease 1997, I85:5 I0-5I6.

30. Meulenbeek P, Herzmanatus J, Smit F, Willemse G, Van der Zanden R: Draaiboek: Geen Paniek, leren omgaan met paniekklachten Utrecht: Trimbos-instituut/GGNet; [Manual: Don't Panic, learn to cope with panic complaints]; 2005.

3I. Meulenbeek P, Herzmanatus J, Smit F, Willemse G, Van der Zanden R: Cursusmap: Geen Paniek, leren omgaan met paniekklachten Utrecht: Trimbos-instituut/GGNet; [Workbook: Don't Panic, learn to cope with panic complaints]; 2005.

32. Meer A Van der, Burgerhout K: Nederlandse versie van de Panic Disorder Severity Scale Amsterdam: Universiteit van Amsterdam; [Dutch version of the Panic Disorder Severity Scale]; 2004. 
33. Houck PR, Spiegel DA, Shear MK, Rucci P: Reliability of the selfreport version of the panic disorder severity scale. Depression and Anxiety 2002, I 5:183-185.

34. Van Vliet IM, Leroy H, Van Megen HJGM: MINI Plus: MINI Internationaal Neuropsychiatrisch Interview: Dutch version 50.0 (in Dutch) Leiden: LUMC; 2000.

35. Leon AC, Olfson M, Portera L, Farber L, Sheehan DV: Assessing psychiatric impairment in primary care with the Sheehan Disability Scale. International Journal of Psychiatry in Medicine 1997, 27:93-105.

36. Rohde P, Lewinsohn PM, Seely JR: Comparability of telephone and face-to-face interviews in assessing axis I and II disorders. American Journal of Psychiatry 1997, I 54:1593-I598.

37. Evans M, Kessler D, Lewis G, Peters TJ, Sharp D: Assessing mental health in primary care research using standardized scales: can it be carried out over the telephone? Psychological Medicine 2004, 34: 157-162.

38. Chambless DL, Caputo GC, Jasin SE, Gracely EJ, Williams C: The Mobility Inventory for Agoraphobia. Behaviour Research and Therapy 1985, 23:35-44.

39. De Beurs E: The assessment and treatment of panic disorder and agoraphobia Amsterdam: Thesis Publications; 1993.

40. Zigmond AS, Sniath RP: The Hospital Anxiety and Depression Scale. Acta Psychiatrica Scandinavica 1983, 67:36I-370.

41. Spinhoven P, Ormel J, Sloekers PPA, Kempen GIJM, Speckens AEM, Van Hemert AM: A validation study of the Hospital Anxiety and Depression Scale (HADS) in different groups of Dutch subjects. Psychological Medicine 1997, 27:363-370.

42. Telch MJ, Brouillard M, Telch CF, Agras WS, Taylor CB: Role of Cognitive Appraisal in Panic-Related Avoidance. Behaviour Research and Therapy 1989, 27:373-383.

43. De Beurs E, Smit JH, Comijs HC: The Panic Opinion List (POL). The reliability and validity of a cognitive measure for panic disorder (in Dutch). Gedragstherapie (Dutch Journal of Behaviour Therapy) 2005, 38: I4I-I54.

44. Beck AT, Steer RA, Brown GK: Manual for the Beck Depression Inventory-II San Antonio, TX: Psychological Corporation; 1996.

45. Van der Does AJW: The Dutch version of the Beck Depression Inventorysecond edition (BDI-II-NL) (in Dutch) Lisse: Swets Test Publishers; 2002.

46. Richter $P$, Werner J, Heerlein A, Kraus A, Sauer H: On the validity of the Beck Depression Inventory: A review. Psychopathology 1998, 31:160-168.

47. Pearlin LI, Schooler C: The structure of coping. Journal of Health and Social Behavior 1978, 19:2-21.

48. Brooks R, EuroQol Group: EuroQol: the current state of play. Health Policy 1996, 37:53-72.

49. Lambert MJ, Burlingame GM, Umphress V, Hansen NB, Vermeersch DA, Clouse GC, Yanchar SC: The Reliability and Validity of the Outcome Questionnaire. Clinical Psychology and Psychotherapy 1996, 3:249-258.

50. de Beurs E, den Hollanders-Gijsman ME, Buwalda V, Trijsburg W, Zit man FG: The Outcome Questionnaire OQ-45. Psychodiagnostic instrument (in Dutch). De Psycholoog (Dutch Journal The Psychologist) 2005, 40:393-400.

51. Hakkaart-Van Roijen L, Van Straten A, Donker M: Manual Trimbos/ iMTA questionnaire for costs associated with psychiatric illness (TIC-P, in Dutch). Rotterdam: Erasmus University; 2002.

52. Saunders JB, Aasland OG, Babor TF, de la Fuente JR, Grant M: Development of the Alcohol Use Disorders Identification Test (AUDIT). WHO collaborative project on early detection of persons with harmful alcohol consumption 1993. Addiction |993, 88:79|-804.

53. Meyer B, Pilkonis PA, Krupnick JL, Egan MK, Simmens SJ, Sotsky SM: Treatment expectancies, patient alliance and outcome: Further analyses from the National Institute of Mental Health Treatment of Depression Collaborative Research Program. Journal of Consulting \& Clinical Psychology 2002, 70: I05 I-I055.

54. Bradley KA, Bush KR, McDonell MB, Malone T, Fihn SD: Screening for problem drinking: comparison of CAGE and AUDIT. Journal of General Internal Medicine 1998, I 3:379-388.

55. Devilly GJ, Borkovec TD: Psychometric properties of the credibility/expectancy questionnaire. Journal of Behavior Therapy and Experimental Psychiatry 2000, 3 I:73-86.

56. Everitt BS: Modern medical statistics: a practical guide New York: Oxford University Press; 2003.
57. Demirtas $\mathrm{H}$ : Simulation driven inferences for multiply imputed longitudinal datasets. Statistica Neerlandica 2004, 58:466-482.

58. StataCorp LP: Stata Statistical Software: Release 9.0. In College Station Texas: Stata Corporation; 2005.

59. Lipsey MW, Wilson DB: The efficacy of psychological, educational and behavioral treatment. American Psychologist 1993. 48: $1|8|-1209$.

60. Jacobson NS, Truax P: Clinical Significance: A Statistical Approach to Defining Meaningful Change in Psychotherapy Research. Journal of Consulting and Clinical Psychology 1991, 59(I): 12-19.

61. Greeven A, Van Balkom AJLM, Visser S, Merkelbach JW, Van Rood YR, Van Dyck R, Van der Does AJW, Zitman FG, Spinhoven P: Cognitive Behavior Therapy and Paroxetine in the Treatment of Hypochondriasis: A Randomized Controlled Trial. American Journal of Psychiatry 2007, I 64:91-99.

62. Haringsma R, Engels GI, Cuijpers P, Spinhoven Ph: Effectiveness of the Coping with Depression course for older adults provided by the community-based mental health care system in the Netherlands: a randomized controlled field trial. International Psychogeriatrics 2006, 18:307-325.

63. Allart-van Dam E: Indicated prevention of depression and prediction of outcome: The 'Coping with Depression' Course. In PhD thesis Nijmegen: Katholieke Universiteit Nijmegen; 2003.

64. Bohlmeijer E, Valenkamp M, Westerhof G, Smit F, Cuijpers P: Creative reminiscence as an early intervention for depression: results of a pilot project. Aging \& Mental Health 2005, 9(4):302-304.
Publish with Bio Med Central and every scientist can read your work free of charge

"BioMed Central will be the most significant development for disseminating the results of biomedical research in our lifetime. "

Sir Paul Nurse, Cancer Research UK

Your research papers will be:

- available free of charge to the entire biomedical community

- peer reviewed and published immediately upon acceptance

- cited in PubMed and archived on PubMed Central

- yours - you keep the copyright
BioMedcentral 